\title{
Examining Various Interpretations of Grice's Cooperative Principle
}

\author{
Yona Dwi Tirta Syafitri ${ }^{1}$, Vira Budiarti ${ }^{2}$, Afriyanti Simamora ${ }^{3}$, and Rizka Aprilya ${ }^{4}$ \\ ${ }^{1}$ U-RAISE Academy, Pekanbaru, Indonesia, 28265 \\ ${ }^{2,3,4}$ Applied Linguistics Center, Pekanbaru, Indonesia, 28265 \\ yonasyafitri@gmail.com
}

\author{
Received : 29 April 2019 \\ Revised : 14 May 2019 \\ Accepted : 30 May 2019

\section{KEYWORDS \\ Cooperative Principle \\ Implicature \\ Pragmatics \\ Relevance \\ Manner}

ARTICLE HISTORY

\begin{abstract}
This study aims to examine various interpretations of the principle of cooperation. The principle of cooperation (CP) was first proposed by H.P. Grice in a series of lectures given in 1967. Grice's most influential contribution to linguistics was his theory of implicature. He illustrated that communication follows what he calls the Cooperative Principle (CP) and argues that the fundamental assumption we make when we speak is that we try to work together to build meaningful conversations (1975). The principle of Grice's Cooperation has become controversial in pragmatics. The main source of controversy related to $\mathrm{CP}$ is that the term "cooperation" is open to different interpretations. This article uses descriptive qualitative methods. As for the results of the study of this article, the principle of cooperation has always tended to focus too much on the term 'cooperation', rather than looking at and examining the principle titles for motivation given by Grice to the mechanisms that he has identified.
\end{abstract}

\section{Introduction}

Language is a tool to communicate between humans in people's lives in the form of speech sounds produced by human speech tools. Language, in its function as a communication tool, is crucial in people's daily lives and for society as a whole (Derin et al., 2019). Communication through language enables everyone to adjust to their physical and social environment. Through language, we can distinguish between one human with another as described Rafiek (2010: 21) says that "language is one of the most distinctive human characteristics that distinguish it from other creatures".

This paper will focus on the way in which the Grice Cooperation Principle is represented in the literature, and interpretation. Our opinion is that there is a tendency that Grice's technical term is confused with the idea of folklinguistic cooperation. Collaboration is a term often used in the linguistic literature to characterize human behavior in conversation. Sometimes it is used in the context of the Grice Cooperation Principle (hereinafter referred to as CP) (Grice, 1975), but it is also used independently.

Cooperative Principle or better known as Maxims is the language rules that govern his actions, the use of his language, and his interpretation of the actions and speech of the interlocutor. In addition, the maxim is also called a pragmatic form based on the principle of cooperation. One branch of pragmatics is implicature, that is, the implicit intention of a language. Pragmatics learn a language with a context that underlies the explanation and understanding (Taguchi \& Roever, 2017).
Grice's Theory on Cooperative Principles leads to the development of "pragmatics" as a separate discipline in language. However, the interpretation of $\mathrm{CP}$ is sometimes problematic because the technical term "cooperation" Grice is often confused between the general meaning of the verb. Grice first introduced the Principle of Cooperation and explained conversational implicature in his article, "Logic and Conversation" (1975). He argues the generation and perception of this implicature is based on the following principle: "Make the contribution of your conversation as needed, at the stage where it takes place, with the accepted purpose or direction of the exchange of conversation in which you are involved" (Grice, 1975: p. 48). The idea of conversational implicature, and the Principle of Cooperation, has been useful and important for some researchers in thinking about how language works in actual use.

The principle of Grice's Cooperation has played a historically important role in pragmatics, because this theory separates pragmatics from linguistics. However, interpretation of the theory is problematic. There seems to be a misinterpretation of the idea of "cooperation" every day, and the technical term Grice.

Proponents of Grice's theory have neglected to explore the ambiguous term "cooperation" and have not yet explained how they interpret and use this concept in their own work. He added that many writers had criticized Grice's theory for misconceptions about the term "cooperation" which was wrong. Ladegaard (2008) explains that because of ambiguity and inconsistency in Grice's own definition of "cooperation" those who adopt this theory often define this term according to their own goals. 
Grice said that humans communicate everyday in a logical and rational way, and cooperation is put into conversation and the audience understands the implications of the speaker's speech by drawing on the assumption of cooperation, context-appropriate information and good background knowledge. In Grice's theory he believes that listeners generally assume that the speaker's words contain sufficient information, and are relevant.

To explain the process underlying the implications, Grice (1975) developed the principles. The principle of cooperation consists of four maxims, namely: Maximum quantity where as one of the cooperative principles is mainly concerned with providing information as needed and which does not contribute more information than is needed. A speaker can be expected to provide enough information and that information cannot exceed the original information used by partners. And say as much as helpful but not more informative or less informative. Finnegan (2004, p.93) defines that the quantity saying states that under normal circumstances, the speaker says sufficient, that they supply no less information and no more than is needed for communication purposes, for example:

A: Where is the bank?

\section{B: Next to the store front.}

It can be seen that information B is informative and contributes sufficiently to question $\mathrm{A}$ about the exact location of the bank, referred to as providing the right amount of information as informative as needed. Don't make information more informative than necessary. In the sense that information must be the same as the information needed.

Quality maxims are donations or contributions according to something that is true, don't say something wrong and say something that has no proof. Grice (1975, p.44) states that when engaging in conversation, Maxim Quality requires that you don't say what you believe is wrong and don't say that you lack sufficient evidence, for example:

\section{A: Where is the Muara Takus temple? \\ B: In Riau}

Here B gives the correct answer that shows the real facts.

The maxim of relevance is is to maintain relevant relevance, using responses that are relevant to the topic of discussion. Finegan (2004) states that this proverb directs the speaker about their speech in such a way that they can be relevant to the ongoing context: Be relevant at the time of speech. A relevant saying is fulfilled when the speaker makes relevant contributions to the topic of the previous utterance. Therefore, Grundy (2000, p.74) said that each participant's contribution must be relevant to the topic of conversation, for example:

A: What about your Goddess exam?

\section{B: Pretty good}

From that example, Dewi's words meet the maxim of relevance, because the answer is relevant to the question.

And the maxim of the manner in which avoid confusing expressions and avoid ambiguity in the sense of speaking briefly and regularly (Grundy, 2000: 74). Therefore, each participant's contribution must be direct, meaning that it should not be vague, ambiguous or excessive. As an example:

\section{A: What do you think about the film?}

B: I really like the romance of every player.

They can playtheir role is like real life.

Answer B is categorized as a saying, he can answer questions from his partner about the film clearly. From the explanation above, we can conclude that although it is very difficult to obey and use all cooperative principles and that is the saying in saying or writing sentences, it is important to follow the principle of cooperation so that communication runs more effectively.

The proverbs above do not determine how one should speak, but rather explain the listener's assumptions about the way the speaker speaks. Bach (2005) believes that Grice introduced these principles as instructions for successful communication.

In Grice's opinion (in Jumadi, 2013: 102-103) distinguishes "four violations of speech maxims that may be carried out in the communication process, namely violating, opting out, clashing, and playing (flout). This violation occurred because the speech participants were indeed unable to use the maxims correctly. The neglect of speech maxim is marked by the reluctance of the participants to cooperate. Motivation that reluctance occurs because they do not want their speech understood by others. The collision occurs because the speech participant tries to implement one maxim, but violates another maxim. Maximum play is done by the speech participants because usually they want the speech to be better understood, or because they are motivated by other factors ".

In a clash of maxims, the speaker cannot complete the adage to respect the listener, and in the latter case, there is a disagreement that is hidden and the speaker can be misled (Grice, 1989: p. 30). In all of these cases, Grice believes that the audience considers the speaker to work together, follow and respect these principles.

Some writers question the maxim of Grice's conversation. For example, Horn (1984) identified only three maxims, and Sperber and Wilson (1986) ignored the structure of the maxims and focused on the idea of relevance. How implicative the conversation is is difficult to distinguish from other conclusions, and how the Grice proverb seems to overlap in a confusing way. 
Sperber and Wilson have produced promising alternatives to this whole area in their work on Relevance Theory (RT) [Sperber and Wilson 86]. The principle of Grice's Cooperation in this context, seems to basically describe Relevance, in both Grice and Sperber and Wilson's senses: Make the contribution of your conversation as needed, at the stage where it occurs, by the purpose or direction of the exchange conversation received in which you are involved. (Although Sperber and Wilson argue that their notion of dier relevance does not imply any agreement on a common goal, or knowledge of accepted norms [Sperber and Wilson 86, pp. 161-163].) RT can thus be seen as a versioning claim Better Relevance is indeed the only saying. RT in any event seems to have a clearer definition of Relevance, have a consistent theory, clearly work, and have avoided the kinds of problems caused by Grice's principles. The main weakness for RT (at least in the 1986 form) is that important concepts of the cognitive effects of speech and processing efforts in understanding speech are both included in cognitive detail that is not theory specific. Sperber and Wilson show in a number of places the amount of naivete about computation, so I suspect the computational implementation must come from other researchers. It only tries to computational implementation of the Theory of Relevance that has caught my attention in this paper is [Poznanski 92] 3, which I do not have obtained a copy.

\section{Method}

To get a meaning that is more representative of Grice's view, the writer looks at the writings on the Principle of Cooperation and its implications in the context of Grice's work as a whole and in the recurring problem is the difference between the meaning of the sentence and the meaning of the speaker, the idea of systematicity in language, and the centrality of rationality towards action human. This article was written using a qualitative descriptive method with the theory of cooperative principles from various contents of the review articles containing information related to the cooperative principle, better known as maxims. This study describes the various cooperative principle classifications, including: quantity, quality, relevance and manner. After analyzing the selected review content from various reference review articles. Analysis by designing various views about Grice theory that many reap the contra in the views of experts. After analyzing the study content chosen in various reference choices, it is found that many have misinterpreted Grice's intentions in his theory of "cooperative principle". In this process, the authors and experts, analyze and compile the cooperative principle theory as a flawed theory, this view will change depending on the reader's understanding in understanding Grice's theory.

\section{Results \& Discussion}

It needs to be known by the reader that these good terms that are used in the context of dialogue analysis can cause problematic interpretations of giving too little information. It may not indicate perfect execution, but this hardly violates the saying. The assumption of perfection leads to the assumption of miscommunication avoidance. In a paper on Human-Computer dialogue, Bernsen, Dybkjer \& Dybkjer (1996) describe a dialogue system that is designed to avoid as much improvement and order of clarification as possible, because this is notoriously difficult to handle in the context of Natural Language Processing. They stated: "However, an important point in what happened next was that the system dialogue was interrupted when users asked questions about the system. Therefore, the key to the success of dialogue design directed by the system is to design dialogue in such a way that users do not need to ask about the system. To do this requires optimizing the system's cooperative dialogue. "Bernsen et al. (1996: 214). Our argument is that knowledge of the philosophical background for the first $\mathrm{CP}$ shows the relatively unimportant cooperation with $\mathrm{CP}$, and allows interpretation that is more in line with Grice's intentions.

It further shows why the $\mathrm{CP}$ transplant from philosophy to linguistics might not be as easy as it seems, and outlines Gricean's view of philosophy. First, the conventions for philosophical writing at the time (especially Grice) made it difficult to read one or two articles separately, because there was little or no 'scene setting'. Second, Grice's general lack of specificity makes it very difficult to pin down his intentions. Researchers need other writings as corroboration for certain interpretations

A more detailed examination of Grice's work on philosophy and language First considering his own views on synthesized philosophy, it makes sense to look for evidence for his views throughout his work, and to consider their importance in language analysis. Second, there are questions about Grice's methodological approach. Because of differences in the objectives of scientific disciplines such as philosophy and linguistics, it is easy to overlook some aspects of work on implicature. In general, linguistics is concerned with how language works. He is not very concerned with proving or refuting philosophical arguments or developing philosophical tools. Grice's (1989b) statement of intent in connection with William James's lecture is interesting in this regard: where the importance of rationality is demonstrated throughout his work.

Crimmins (2000: 456) supports the view that the development of philosophical methodologies is very important for Grice, and there is plenty of evidence for this throughout his work. The concept of implicature was first introduced in Grice (1961), for the purpose of investigating the concept of the sensory datum in the context of the Theory of Perception (Travis 1996). Implications have since been used to explain the properties of indicative conditions (William James's lecture, published as Grice 1989c); temporal meanings and, and aspects of prejudice and 'truth value gaps' (Grice 1981); and why certain sentences are difficult to classify in true and false 
dichotomies (eg Grandy 1989). The implicature itself is also 'defined' in terms of the classic tool of cancellation and release, using the concepts of conventionality and nonconventional10.

In his article, Ladegaard (2008) argues that both the human and pragmatic interactions as well as all the linguistic awareness needed for the perception and interpretation of meaning in any communicative behavior must be discussed in any cooperative collaboration theory considering any semantic aspects of speech and then making it clear based on pragmatics, or according to the context that helps us to interpret the topic of the speaker also adds that to understand the meaning of the speaker accurately in an interaction, and interpret the meaning that underlies speech, the use of these cues is very important.

Ladegaard (2008) states that instead of applying traditional views to language and communication offered in Pragmatics, where human interaction is seen as naturally lacking and problematic, broader views must be considered. He mentioned that Grice was very biased towards cooperation. Grice's assumption is that people communicate logically, and all try to be "good" communicators.

However, Ladegaard's analysis (2008) contradicts Grice's position. He claims "human interaction may be irrational and illogical, and that resistance and noncooperation can be adopted as discursive strategies that are preferred, and that people who interact seem to try their best to become 'bad' communicators."

In his study Ladegaard (2008), think of two types of cooperation related to Gricean's theory: "sharing social goals and sharing linguistic goals". In this analysis, the teacher interviews students about their future careers. The aim is to investigate the relationship between attitudes and behavior in language.

\section{Conclusion}

This study discussed the understanding that student dialogue is non-cooperative and non-accommodating, and that this is the preferred discourse strategy used by students. In other words, in their interviews with students, try to miscommunicate rather than communicate successfully. This study believes that social and psychological conditions determine the intensity of people to work together in a conversation or not. Therefore, this present study saw that Grice's cooperative principle has a tendency to focus on the term 'cooperation', rather than looking at and examining the principle titles for motivation given by Grice to the mechanisms that he has identified.

\section{References}

Abdulla, I. A., \& Majeed, S. H. (2019). A Pragmatic Analysis of Some Quranic Verses in Light of Grice's Cooperative Principle. Journal of University of Human Development, 5(3), 127-133.
Derin, T., Deliani, S., Fauziah, N., Afifah, N., \& Hamuddin, B. (2019). Indonesians' Tendency to Refer Abbreviation as Acronym: Types of Abbreviation as Word Formation Process. Globish: An EnglishIndonesian Journal for English, Education, and Culture, 8(2).

Freihat, A. A., Qwaider, M. R., \& Giunchiglia, F. (2018, March). Using grice maxims in ranking community question answers. In Proceedings of the Tenth International Conference on Information, Process, and Knowledge Management, eKNOW 2018, Rome, Italy (pp. 38-43).

Grice, H. P., Cole, P., \& Morgan, J. (1975). Logic and conversation. 1975, 41-58.

Grice, H.P. (1957). 'Meaning'. The Philosophical Review. 66. $377-388$

Grice, H.P. (1961). 'The causal theory of perception'. The Aristotelian Society: Proceedings, Supplementary Volume, vol.35. 121-153.

Grice, H.P. (1968). Utterer's meaning, sentence meaning and word meaning. Foundations of Language 4. 225242.

Grice, H.P. (1969). Utterer's meaning and intentions. The Philosophical Review 78. 147-177.

Grice, H.P. (1975). 'Logic and conversation' In Cole, P. \& Morgan, J. (eds.) Syntax and Semantics, Volume 3. New York: Academic Press. pp. 41-58.

Hadi, A. (2013). A critical appraisal of Grice's Cooperative Principle. Open journal of modern linguistics, 3(01), 69.

Hanitzsch, T. (2007). Deconstructing journalism culture: Toward a universal theory. Communication theory, 17(4), 367-385.

Jumadi. 2013. Wacana, Kekuasaan, dan Pengajaran Bahasa.Yogyakarta: Pustaka Pelajar.

Ladegaard, H. J. (2008). Pragmatic cooperation revisited: Resistance and non-cooperation as a discursive strategy in asymmetrical dis- courses. Journal of Pragmatics, in Press.

Leech, G. (1983). N., 1983, Principles of Pragmatics, London and New York.

Muhammad, A. A., \& Karim, H. A. (2019). An Analysis of Grice's Cooperative Principles in Some Selected English TV Interviews. Journal of the University of Garmian, 6, 1.

Rafiek, M. (2010). Dasar Dasar Sosiolinguistik. Yogyakarta: Pustaka Prisma.

Sarangi, S. K., \& Slembrouk, S. (1992). Non-cooperation in communi- cation: A reassessment of Gricean 
Pragmatics. Journal of Pragmatics, 17, 117-154. doi:10.1016/0378-2166(92)90037-C

Sperber, D. \& Wilson, D. (1986). Relevance. Oxford: Blackwell.

Taguchi, N., \& Roever, C. (2017). Second language pragmatics. Oxford University Press.

Tang, Y. (2018). Evaluating Argumentative English Writings in the Light of Grice's "Cooperative Principles". Journal of Contemporary Educational Research, 2(4), 1-5.

Wu, Y. (2019, July). A Literature Review on Cooperative Principle. In 4th International Conference on Contemporary Education, Social Sciences and Humanities (ICCESSH 2019). Atlantis Press. 